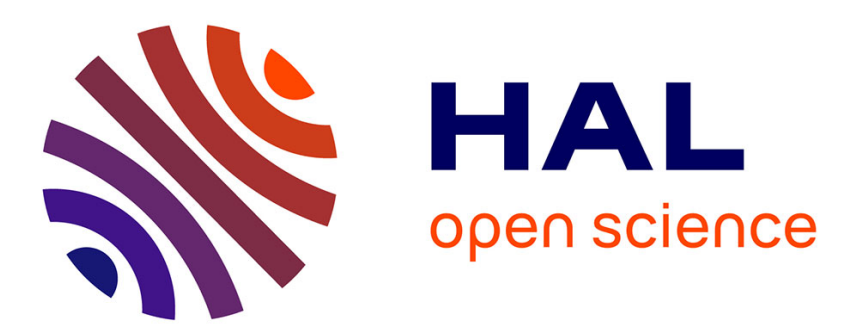

\title{
TerraSAR-X dual-pol time-series for mapping of wetland vegetation
}

\author{
Julie Betbeder, Sébastien Rapinel, Samuel Corgne, E. Pottier, Laurence
}

Hubert-Moy

\section{- To cite this version:}

Julie Betbeder, Sébastien Rapinel, Samuel Corgne, E. Pottier, Laurence Hubert-Moy. TerraSAR$\mathrm{X}$ dual-pol time-series for mapping of wetland vegetation. ISPRS Journal of Photogrammetry and Remote Sensing, 2015, 107, pp.90-98. 10.1016/j.isprsjprs.2015.05.001 . hal-01155318

\section{HAL Id: hal-01155318 \\ https://hal-univ-rennes1.archives-ouvertes.fr/hal-01155318}

Submitted on 31 Aug 2015

HAL is a multi-disciplinary open access archive for the deposit and dissemination of scientific research documents, whether they are published or not. The documents may come from teaching and research institutions in France or abroad, or from public or private research centers.
L'archive ouverte pluridisciplinaire HAL, est destinée au dépôt et à la diffusion de documents scientifiques de niveau recherche, publiés ou non, émanant des établissements d'enseignement et de recherche français ou étrangers, des laboratoires publics ou privés. 


\title{
TerraSAR-X dual-pol time-series for mapping of wetland vegetation
}

\author{
Julie Betbeder ${ }^{\mathrm{a}}$, Sébastien Rapinel ${ }^{\mathrm{a}, \mathrm{b}}$, Samuel Corgne ${ }^{\mathrm{a}}$, Eric Pottier ${ }^{\mathrm{c}}$, Laurence Hubert- \\ Moy $^{\mathbf{a}}$ \\ ${ }^{a}$ LETG Rennes COSTEL UMR CNRS 6554 /OSUR, Université Rennes 2, Place du recteur Henri Le Moal, \\ 35043, Rennes Cedex, France ; \\ ${ }^{\text {b} E C O B I O ~ U M R ~ C N R S ~ 6553 / O S U R, ~ C a m p u s ~ d e ~ B e a u l i e u, ~} 35042$ Rennes Cedex, France.
}

'IETR UMR CNRS 6164, Université de Rennes 1, Campus Beaulieu-bât 11D, 263, av du général Leclerc, CS 74205, 35042 Rennes Cedex, France.

Keywords: Wetlands, Synthetic Aperture Radar (SAR), TerraSAR-X imagery, multi-temporal classifications, Support Vector Machine classifier.

Address all correspondence to: Betbeder Julie, Université Rennes 2, LETG Rennes COSTEL, Université Rennes 2, Place du Recteur Henri Le Moal, 35043 RENNES cedex; Tel: +33 (0)2 9914 18 47; E-mail: betbederjulie@gmail.com

\begin{abstract}
.
Mapping vegetation formations at a fine scale is crucial for assessing wetland functions and for better landscape management. Identification and characterization of vegetation formations is generally conducted at a fine scale using ecological ground surveys, which are limited to small areas. While optical remotely sensed imagery is limited to cloud-free periods, SAR time-series are used more extensively for wetland mapping and characterization using the relationship between distribution of vegetation formations and flood duration. The aim of this study was to determine the optimal number and key dates of SAR images to be classified to map wetland vegetation formations at a 1:10,000 scale. A series of eight dual-polarization TerraSAR-X images (HH/VV) was acquired in 2013 during dry and wet seasons in temperate climate conditions. One polarimetric parameter was extracted first, the Shannon entropy, which varies with wetland flooding status and vegetation roughness. Classification runs of all the possible combinations of SAR images using different $\mathrm{k}$ (number of images) subsets were performed to determine the best combinations of the Shannon entropy images to identify wetland vegetation formations. The classification runs were performed using Support Vector Machine techniques and were then analyzed using the McNemar test to investigate significant
\end{abstract}


differences in the accuracy of all classification runs based on the different image subsets. The results highlight the relevant periods (i.e. late winter, spring and beginning of summer) for mapping vegetation formations, in accordance with ecological studies. They also indicate that a relationship can be established between vegetation formations and hydrodynamic processes with a short time-series of satellite images (i.e. 5 dates). This study introduces a new approach for herbaceous wetland monitoring using SAR polarimetric imagery. This approach estimates the number and key dates required for wetland management (e.g. restoration) and biodiversity studies using remote sensing data.

Keywords. SAR imagery, vegetation formations, change detection, multitemporal image analysis, SVM.

\section{Introduction}

Wetlands provide an abundance of ecological services that are valuable to society (Gren et al., 1994). They play a key role in flood and water-pollution control, carbon sequestration, and biodiversity conservation (Keddy et al., 2009; Mitsch and Gosselink, 2007). Spatially explicit wetland inventories are an instructive source of information for planners to determine wetland status, monitor these environments and identify important habitats for wildlife, economic interests and other functions (Clement et al., 1996).

Functional assessment of wetlands requires characterizing vegetation formations at a fine scale (1:10,000 or greater) (Maltby and Barker, 2009). Since wetlands are spatially and temporally dynamic, the distribution of vegetation formations in these environments is mainly controlled by hydrological processes. Identification and mapping of wetland plant species is generally performed at a fine scale using ecological ground surveys (Duncan et al., 1999; Bouzillé et al., 2001; Loucougaray et al., 2004; Sawtschuk and Bioret, 2012; Dumont et al., 2012), but are limited to small areas of a few hectares.

While remotely sensed data are often used to monitor ecosystems and biodiversity (Lang et al., 2013), their potential to support monitoring of protected areas remains underexploited (Nagendra et al., 2013). Most studies use aerial photographs and optical data to map wetland vegetation (Chidley and Drayton, 1986; Alexandridis et al., 2009; Davranche et al., 2010; Rapinel et al., 2014). For example, some studies showed the potential of optical data time-series such as SPOT-5 (Davranche et al., 2010) or Landsat (Civco et al., 2006) images for wetland vegetation mapping. Other studies highlight the high potential of the 
combined use of LIDAR data and multispectral imagery to map wetland habitats (Ecker et al., 2010; Rapinel et al., in press). Optical image time-series are generally more reliable for identifying wetland vegetation types with a similar physiognomy (e.g. grasslands) since they include the dynamic nature of wetlands (Schuster et al., 2015). However, for operational mapping, optical data are unsuitable for monitoring wetland dynamics as they are limited to cloud-free periods (Claverie et al., 2012). Consequently, acquisition of optical intra-annual time-series is unpredictable and not constant over time (Verbesselt et al., 2010). Conversely, Synthetic Aperture Radar (SAR) time-series are not sensitive to visibility conditions and can be acquired day or night (Schuster et al., 2015).

In recent years, SAR images have been used more extensively for wetland mapping and characterization (Hess et al., 2003; Corcoran et al., 2011; Schmitt et al., 2012; Betbeder et al., 2014 a; Betbeder et al., 2014 b) using the relationship between distribution of vegetation formations and flood duration. SAR data are well-known for their ability to detect open water (Marechal et al., 2012), water below forest canopy (Frappart et al., 2005) and emergent vegetation (Betbeder et al., 2014 b). These characteristics are directly linked to the backscattering mechanisms that occur between the radar signal and natural surfaces (i.e. single bounce for open water and double bounce for water below forest canopy and emergent vegetation). SAR images are often used to classify forested wetland vegetation in tropical areas (Touzi et al., 2004; Evans and Costa 2013; Betbeder et al., 2014 a). For example, Hess et al. (2003) used two JERS-1 images acquired during dry and wet seasons to map flooded forests in the Amazon basin. SAR sensors such as JERS-1 and ALOS PALSAR L-bands are well suited to map flooded forests since they can penetrate forest canopy and detect the water below.

However, few studies have focused on the evaluation of SAR and optical time-series to identify vegetation formations in herbaceous wetlands at a fine scale under temperate climate conditions. Semi-natural grassland habitats defined by a floristic composition gradient are difficult to identify using Earth observation techniques, since they have similar spectral signatures (Feilhauer et al., 2013). Several studies have shown the benefit of remotely sensed data to characterize such ecosystems. For example, Buck et al. (2013) used multispectral time-series and ancillary layers (e.g. soil types, slope) to map Natura 2000 grassland habitats. Franke et al. (2012) showed the potential of multispectral time-series for mapping use intensity of grasslands and consequently their conservation status. However, problems encountered using multispectral time-series for semi-natural habitat mapping include intraclass spectral variability due to different phenological stages and continuous transitions 
between habitats, which decrease classification accuracy (Stenzel et al., 2014). With the emergence of very-high-resolution SAR sensors such as TerraSAR-X and RADARSAT-2, new studies emerged that characterized dry grasslands (Hill et al., 2005; Dusseux et al., 2012; Schuster et al., 2015) and wet grasslands (Betbeder et al., 2014 b). Farghaly et al. (2014) showed that multi-temporal dual-pol TerraSAR-X images improve classification accuracy in discriminating grasslands from crops compared to single polarization TSX images. Bargiel (2013) demonstrated that multi-temporal TerraSAR-X data, particularly backscattering coefficients in $\mathrm{HH}$ and VV, are relevant for identifying semi-natural grasslands. Schuster et al. (2015) showed that TerraSAR-X time-series are relevant for mapping herbaceous wetland vegetation. While herbaceous wetland vegetation types can be similar, they can be discriminated by monitoring their intra-annual phenology using temporal profiles derived from SAR images (Betbeder et al., 2014 b, Shuster et al., 2015). In most studies, the backscattering coefficients of radar signals are used to discriminate heterogeneous grassland patterns. Polarimetric parameters have been poorly explored for this purpose (Dusseux et al., 2014; Betbeder et al., 2014 b). However, Betbeder et al. (2014 b) evaluated several parameters (backscattering coefficients and polarimetric parameters) derived from six dualpol TerraSAR-X images to precisely map the distribution of vegetation formations in wetland areas by considering annual flood duration, since the distribution of vegetation formations depends strongly on past and present hydrodynamic conditions. They show that vegetation formations can be accurately identified from the classification of Shannon Entropy (SE) temporal profiles derived from TerraSAR-X images. They demonstrate the importance of using polarimetric parameters instead of backscattering coefficients alone or combined.

While SAR data takes less time to pre-process than optical data, e.g. no atmospheric corrections or cloud masking with SAR data (Schuster et al., 2015), habitat mapping using remote sensing data remains more expensive than field surveys (Vanden Borre et al., 2011). Consequently, it is necessary to determine the optimal number and key dates of SAR images necessary to classify wetland vegetation formations with high accuracy and reasonable cost.

In recent years, the utility of multiple images for increasing classification accuracy has been analyzed in remote sensing studies. One common way to determine the optimal number of images necessary to classify land use or land cover in remotely sensed time-series is to compare accuracy measures (i.e. Kappa index, overall accuracy (OAA)) of classification runs using different numbers of images (Van Niel and McVicar 2004; Corgne et al., 2014). Some studies performed a z-test to include a measure of significance in comparing classification 
runs (Sader et al., 1995; Murakami et al. 2001). However, this test assumes that samples are independent, which is not the case when using the same set of samples to validate several classifications (Eliasziw and Donner 1991). More robust tests are necessary when considering related pairs of validation samples. One interesting study evaluated the optimal number of multispectral time-series for mapping grassland vegetation types based on the McNemar test (Schmidt et al., 2014). This test, based on a binary $2 \times 2$ contingency matrix, shows the proportion of pixels correctly and incorrectly classified with two classification runs (Foody 2004) and allows the use of dependent samples. To the best of our knowledge, this method has never been applied to determine the optimal number of SAR polarimetric data necessary for mapping herbaceous wetland vegetation types.

The aim of this study was to determine the optimal number and key dates of SAR images to be classified to map wetland vegetation formations at a 1:10,000 scale. For this purpose, we processed a time-series of eight TerraSAR-X images acquired under temperate climate conditions during the same hydrological year. We first extracted one polarimetric parameter from the images, SE, which varies with wetland flooding status and vegetation roughness. This indicator is known to efficiently map vegetation formations in herbaceous wetlands (Betbeder et al., 2014). Following Schmidt et al. (2014), we performed several classification runs to test all possible image combinations to determine the best combinations of the SE images derived from the TerraSAR-X data to identify wetland vegetation formations. The classification runs were performed using Support Vector Machine (SVM) techniques (Zhang, 2001; Foody and Mathur, 2004; Mountrakis et al., 2011) and were analyzed using the McNemar test to investigate significant differences in the accuracy of all classification runs based on the image subsets.

\section{Materials and methods}

\subsection{Study site}

The investigated area is part of a Long-Term Ecological Research (LTER) site named "Pleine Fougères," located on the southern portion of the Bay of Mont-Saint-Michel, France, and referenced in the LTER-Europe (lterEurope.net) and ILTER networks (Fig. 1). This 670 ha site contains a broad river floodplain that is a Natura 2000 and RAMSAR protected area (http://osur.univ-rennes1.fr/za-armorique/page.php?107). 
Research in the wetland area is devoted to studying variations in flooding and their impacts on wetland functions. This area forms a homogeneous alluvial deposit with low elevation $( \pm 7 \mathrm{~m})$. Local authorities manage water levels to provide a suitable habitat for many aquatic bird species and to facilitate pike reproduction.

The wetland area is mainly composed of low herbaceous vegetation. The plant communities are structured according to flood duration and are conditioned by water management and micro-topography. The area that floods the longest (at least 3 months/year) in the wetland is covered with grasslands where Glyceria fluitans, Carex hirta and Eleocharis palustris grow. Two-thirds of the marsh area is flooded less than 3 months/year and is composed of hygrophilic and meso-hygrophilic grasslands dominated by Eleocharis palustris and Alopecurus geniculatus. The elevated areas associated with the alluvial ridge at the foot of the slope along the main river channel are composed of mesophilic grasslands dominated by Lolium perenne.

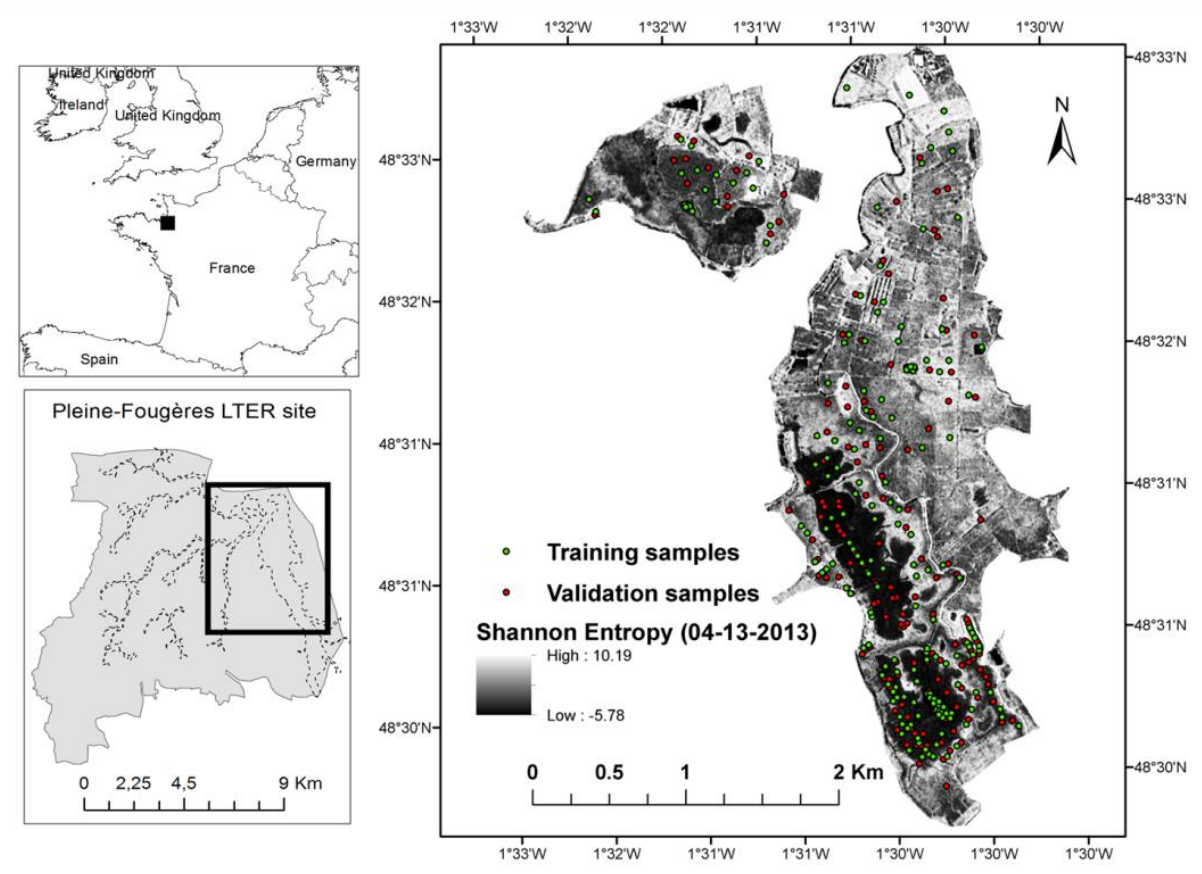

Figure 1. Location of the study site and locations of training and validation samples

\section{$2.2 \quad$ Data}

A series of eight dual-polarization TerraSAR-X images was acquired in 2013 during dry and wet seasons in High Resolution Spotlight mode with HH and VV polarizations (Table 1). An 
incidence angle of $37^{\circ}$ was chosen to maximize vegetation penetration and water detection. Radar images were collected during the hydrological period from February to September.

Table 1. Characteristics of the TerraSAR-X images acquired

\begin{tabular}{|l|l|}
\hline Ground resolution & $1.50 \mathrm{~m}$ \\
\hline Azimuth resolution & $2.2 \mathrm{~m}$ \\
\hline Polarization & Dual (HH-VV) \\
\hline Mode & High Resolution Spotlight \\
\hline Incidence angle & $37^{\circ}$ (right ascending) \\
\hline Coverage & $5 \mathrm{~km} \times 10 \mathrm{~km}$ \\
\hline Dates (M-D-Y) & $02-16-2013$ \\
& $03-10-2013$ \\
& $04-15-2013$ \\
& $05-04-2013$ \\
$05-15-2013$ \\
$06-17-2013$ \\
& $07-20-2013$ \\
& $09-20-2013$ \\
\hline
\end{tabular}

Field observations were conducted in 262 plots to calibrate and validate the image classification (around 40 per vegetation formation) (Fig. 1). Plant species composition was recorded in square plots $(4 \times 4 \mathrm{~m})$ randomly distributed throughout the study site and located using GPS with an accuracy of $\pm 5 \mathrm{~m}$. Half of the plots were used as training samples and the other half as validation samples.

\subsection{Image pre-processing}

A $2 \times 2$ covariance $\left(\mathrm{C}_{2}\right)$ matrix was first extracted from the scattering matrix images using PolSARpro v4.0 software (Pottier and Ferro-Famil, 2012). A refined Lee filter was applied using a window of $7 \times 7$ pixels to reduce speckle noise (Lee, 1981). The geocoding process was directly applied to the elements of the $2 \times 2 \mathrm{C}_{2}$ matrix, which are independent of the polarimetric absolute phase (Lee and Pottier, 2009) (Fig. 2).

SE, which corresponds to the sum of two contributions related to the intensity and the degree of polarization (Lee and Pottier, 2009), was then calculated from the $\mathrm{C}_{2}$ matrix. SE 
measures the disorder encountered in polarimetric SAR images. Each pixel in the TerraSAR$\mathrm{X}$ images is defined as a complex 2D target vector $k$ that follows a 2D circular Gaussian process with a mean of zero and a covariance matrix $C_{2}$ :

$$
P_{C_{2}}(\underline{k})=\frac{1}{\pi^{2}\left|C_{2}\right|} \exp \left(\underline{k}^{\mathrm{T} *} * C_{2}^{-1} \underline{\mathrm{k}}\right)
$$

where $\mathrm{T} *$ stands for transpose-conjugate.

The intensity $\left(I_{\mathrm{C}}\right)$ and degree of polarization $\left(P_{\mathrm{C}}\right)$ are defined from the $C_{2}$ averaged using the following formulas:

$$
I_{C}=T_{\mathrm{r}}\left(C_{2}\right) \text { and } P_{C}=\sqrt{1-4 \frac{\left|C_{2}\right|}{T_{\mathrm{r}}\left(C_{2}\right)^{2}}}
$$

where $T_{\mathrm{r}}($.$) and |.| stand for the trace and determinant of the matrix, respectively.$

Shannon Entropy $S E$ is defined for a general density function by:

$$
S\left|P_{C}(\underline{k})\right|=\int P_{C}(\underline{k}) \log \left[P_{C}(\underline{k})\right] d \underline{k}
$$

where $\int(). d \underline{k}$ stands for complex 2D integration. In the case of a circular Gaussian process, $S E$ is decomposed as the sum of two terms: intensity contribution $\left(S E_{\mathrm{I}}\right)$, which depends on total backscattered power, and polarimetric contribution $\left(S E_{\mathrm{P}}\right)$, which depends on the Barakat degree of polarization $P_{\mathrm{C}}$ (Réfrégier and Morio, 2006). In other words, SE measures the randomness of scattering of a pixel, which can be due to variation in backscattering power or polarization.

$$
\begin{gathered}
S E=\log \left(\pi^{2} e^{2}\left|C_{2}\right|\right)=S E_{I}+S E_{P} \\
S E_{I}=2 \log \left(\frac{\pi e I_{C}}{2}\right)=2 \log \left(\frac{\pi e T_{r}\left(C_{2}\right)}{2}\right) \\
\mathrm{SE}_{\mathrm{P}}=\log \left(1-\mathrm{P}_{\mathrm{C}}^{2}\right)=\log \left(4 \frac{\left|\mathrm{C}_{2}\right|}{\mathrm{T}_{\mathrm{r}}\left(\mathrm{C}_{2}\right)^{2}}\right)
\end{gathered}
$$

\subsection{Image processing}

We aimed to test all possible image combinations to determine the best combinations of the SE images derived from the TerraSAR-X data to identify six wetland vegetation 
formations (i.e. wooded areas, ponds, long-flooded grasslands, hygrophilic grasslands, mesohygrophilic grasslands, and mesophilic grasslands). In other words, we evaluated all possible combinations of dates for wetland vegetation mapping for each $\mathrm{k}$ number of images (1-8 dates) (Fig. 2). We tested 255 combinations using 8 SE images. Each subset of SE images was classified using the SVM technique (Zhang, 2001; Foody and Mathur, 2004; Mountrakis, 2011) with a Gaussian kernel. SVM techniques are commonly used and are known to efficiently classify remotely sensed time-series (Zheng et al., 2004; Tigges et al., 2013; Schuster et al., 2015). A Gaussian kernel was used because it is classifies multi-temporal TerraSAR-X data more effectively than other methods for wetland vegetation mapping (Betbeder et al. 2014 b). Classification accuracy was defined using overall accuracy (OAA). All classification runs were then analyzed using the McNemar test (Agresti 2007). This test is known for its efficiency in comparing classification accuracies to determine the best acquisition date combinations (Alcantara et al., 2012; Schmidt et al., 2014). The McNemar test enables using the same set of samples to validate several classifications (Agresti, 2007). It is based on the proportion of correctly and incorrectly allocated pixels in a binary $2 \times 2$ contingency matrix (Foody, 2004). Following Schmidt et al. (2014), this test was used to investigate significant differences in the accuracy of classification runs based on the different image subsets. For each k subset (1-8 acquisition dates), the classification selected an OAA close to the mean OAA. Each classification was performed using different combinations for each $\mathrm{k}$ subset and tested to see if it was significantly higher or lower than the mean OAA. A significant difference was assumed if $\chi^{2}$ exceeded the critical value of 3.14 (one degree of freedom and significance level of $\alpha=0.05$ ). Thus, we classified each classification run as (i) significantly higher, (ii) insignificantly or (iii) significantly lower than mean OAA.

A "ratio of saturation" was used to distinguish the best tradeoff between the number of image acquisitions and OAA. According to Schmidt at al. (2014), the ratio of saturation includes "for each $\mathrm{k}$ the mean OAA of all significantly improved classification runs and the mean OAA on all insignificantly influenced classification runs".

$$
\begin{aligned}
& \text { ratio of saturation }=\frac{\overline{O A A} \text { no sig }}{\overline{\overline{O A A} \text { pos sig }}} \\
& \overline{O A A}=\frac{1}{p} \sum_{i=1}^{p} \text { OAA pos sig } i
\end{aligned}
$$




$$
\overline{O A A}=\frac{1}{q} \sum_{i=1}^{q} O A A \text { no sig } i
$$

Where $p$ is the number of all significantly improved classification runs and $q$ is the number of all insignificantly influenced classification runs.

If the ratio of saturation exceeds 0.95 , the addition of acquisition dates does not significantly improve OAA. All analyses were performed using the $\mathrm{R} 2.9 .0$ software package ( $\mathrm{R}$ Development Core Team, 2010).

Once the best tradeoff between the number of acquisition dates and OAA was selected, we analyzed the number of occurrences of the "best dates" for all classification runs with an OAA above the saturation ratio for the best $\mathrm{k}$ classifications. For the best classification combination, we calculated the kappa index which expresses the proportional reduction in error generated by a classification process compared with the error of a completely random classification (Congalton, 1991). The kappa index is commonly used to assess prediction errors in conservation presence/absence models (Fielding and Bell, 1997).

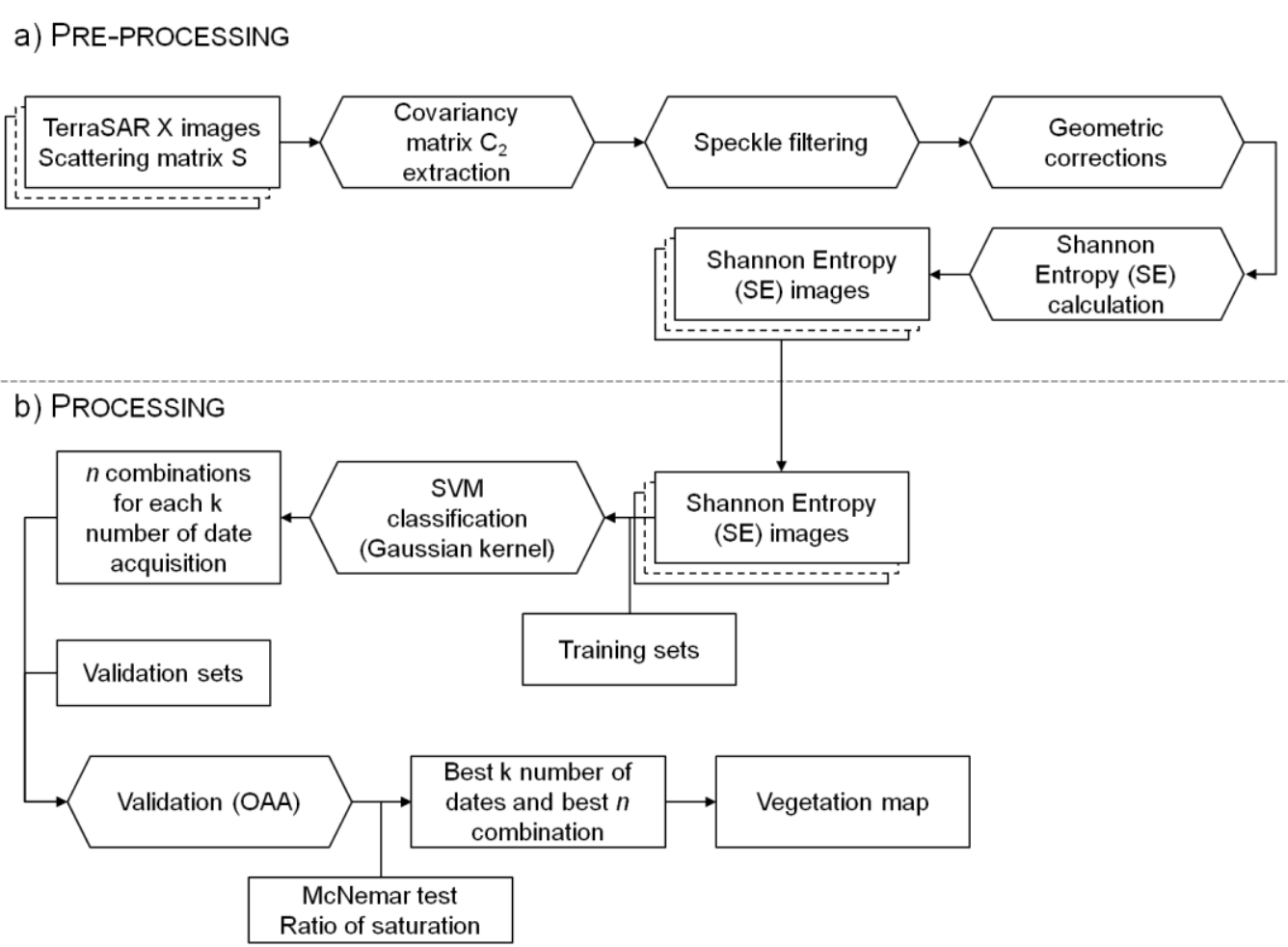

Figure 2 : Workflow of image pre-processing and processing 


\section{Results}

The more acquisition dates, the higher the mean OAA is (Fig. 3). Moreover, variability in OAA decreases as the number of acquisition dates increases. The maximum mean OAA is around $95 \%$ with 8 dates, decreasing to $45 \%$ with 1 date. The ratio of saturation is reached with 5 acquisition dates, with a mean OAA of 95\%. Thus, 5 images correspond to the best tradeoff between the number of acquisition dates and the OAA. Very good results are also achieved with 6-8 images. Good results are achieved with only 2-4 images, but with few image combinations. The best combination of dates using 5 dates is February, April, May, June, and July. The McNemar test showed no significant differences in OAA when using more than 4 dates.

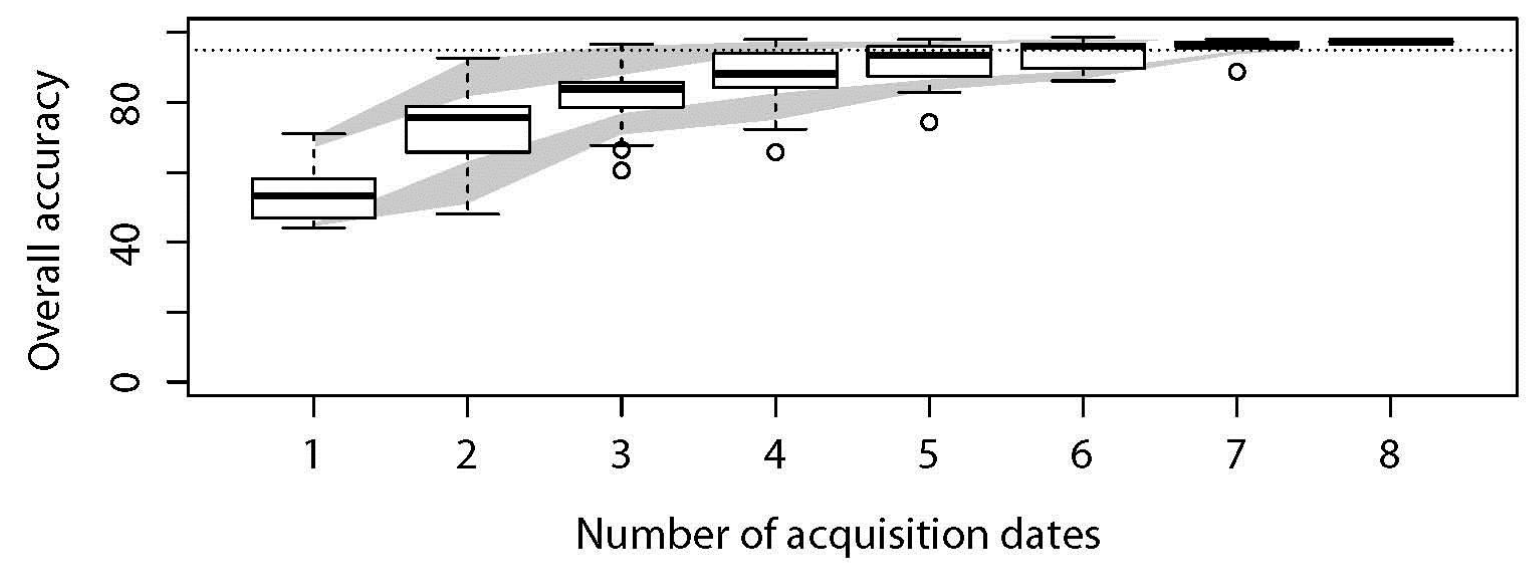

Figure 3: Boxplots of overall accuracy of all classification runs (date combinations of 8 TerraSAR-X images) as a function of the number of acquisition dates ( $k$ subsets). Gray areas represent classification accuracies significantly higher or lower than the mean according to the McNemar test. The horizontal dotted line represents the ratio of saturation.

Figure 4 presents the number of occurrences of the "best dates" for all the classification runs with an OAA above a saturation ratio level of 0.95 , for $4 \mathrm{k}$-subsets $(\mathrm{k}=2, \mathrm{k}=3, \mathrm{k}=4$ and $\mathrm{k}=5$ images). Spring images are always included in the best image combinations (Fig. 4). The best images to identify vegetation formations in wetlands are those acquired at the beginning of the year and in late winter and spring. SAR images acquired at the beginning and end of summer are included in the best combination dates of 3, 4 and 5 images. 


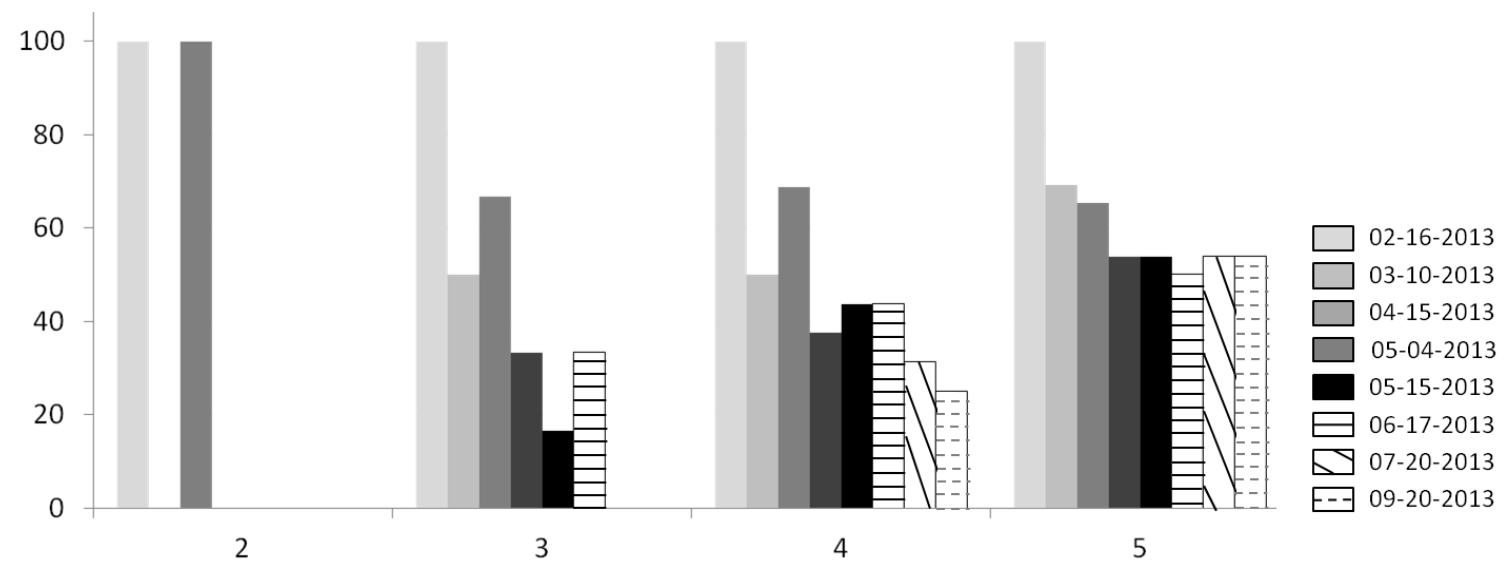

Figure 4: Number of occurrences of the "best dates" for classification runs with an overall accuracy above a saturation ratio $\geq 0.95$ for four $k$-subsets $(k=2-5$ images $)$.

Figure 5 and Table 4 detail the classification results obtained using five TerraSAR-X images acquired in February, April, May, June and July. The confusion matrix shows that all the vegetation-formation classes considered achieve high detection accuracy (Table 2). The "Ponds" class has an excellent overall accuracy detection rate (i.e. 100\%). Misclassification errors occur between the "Meso-hygrophilic grasslands" and "Hygrophilic grasslands" classes because these vegetation formations are similar and spatially close in wetland areas. There is also confusion between the "Mesophilic grasslands" and "Wooded areas" classes, which could be explained by the absence of low values in the SE temporal profiles, induced by a flood period.

The spatial distribution of vegetation formations mapped at 1:10,000 scale is presented in figure 5. Forested areas are well identified, particularly the riverine areas. One also observes a correspondence between the gradient detected in herbaceous wetlands (from long-flooded grasslands to mesophilic grasslands) and micro-topographic variations, and thus hydrodynamic processes. 


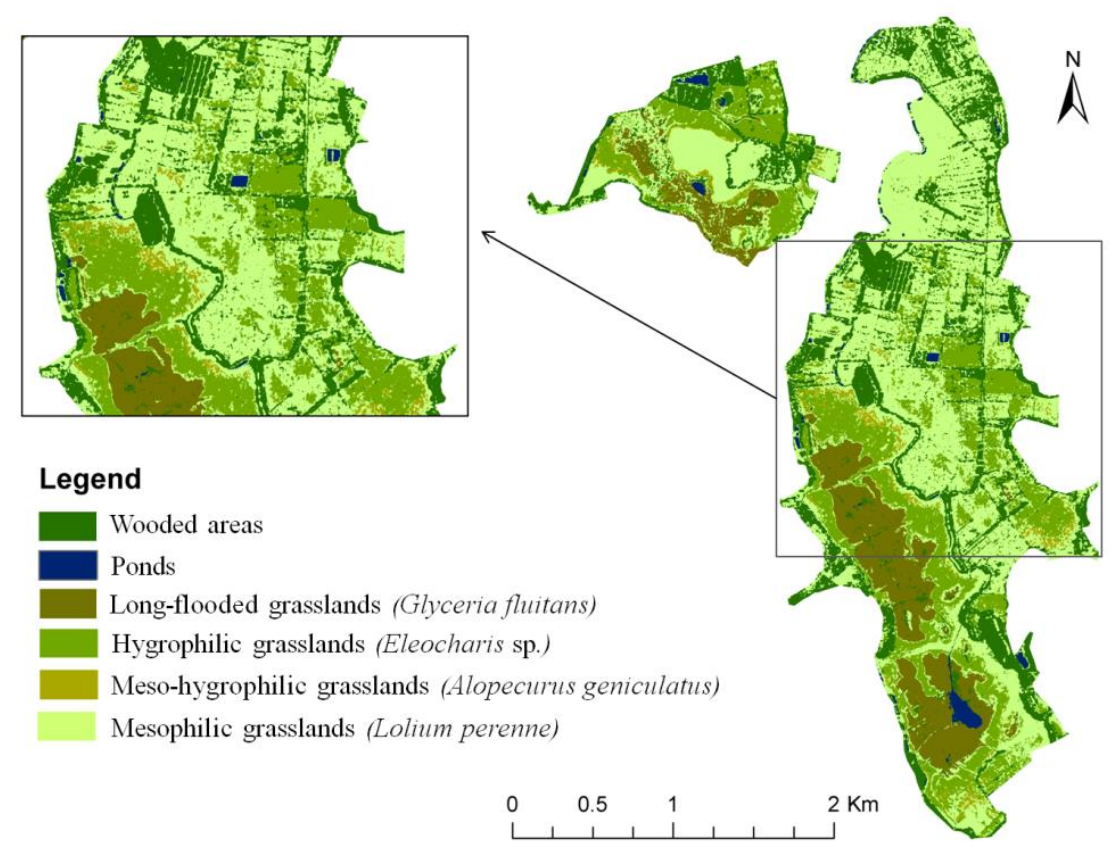

Figure 5. Map of the distribution of vegetation formations in wetland areas obtained using five TerraSAR$\mathbf{X}$ images (February, April, May, June and July). The classification was performed by combining the Shannon Entropy index and the SVM classifier using a Gaussian kernel.

Table 2. Confusion matrix between the vegetation formation classification derived from five TerraSAR-X multi-temporal images (lines) and the validation set (columns). The classification was performed by combining the Shannon Entropy index and the SVM classifier using a Gaussian kernel.

\begin{tabular}{|c|c|c|c|c|c|c|c|c|c|}
\hline \multirow[b]{2}{*}{ Classification } & \multicolumn{8}{|c|}{ Validation } & \multirow[b]{2}{*}{ Over-detection } \\
\hline & Code & 1 & 2 & 3 & 4 & 5 & 6 & Total & \\
\hline Wooded areas & 1 & 261 & & & & 18 & & 279 & 0.9 \\
\hline Ponds & 2 & & 270 & & & & & 270 & 0.00 \\
\hline Hygrophilic grasslands & 3 & & & 81 & & & 9 & 90 & 0.90 \\
\hline Long flooded grasslands & 4 & & & & 180 & & & 180 & 0.00 \\
\hline Mesophilic grasslands & 5 & & & & & 270 & & 270 & 0.00 \\
\hline Meso-hygrophilic grasslands & 6 & & & 9 & & & 270 & 279 & 0.90 \\
\hline Total of column & & 261 & 270 & 90 & 180 & 281 & 279 & & \\
\hline Under-detection & & 0.00 & 0.00 & 0.90 & 0.00 & 0.90 & 0.90 & & \\
\hline Overall accuracy & $95 \%$ & & & & & & & & \\
\hline Kappa index & 0.94 & & & & & & & & \\
\hline
\end{tabular}

\section{Discussion}

The vegetation map created at a 1:10,000 scale is based on a method that highlights detection of flood duration with a SE time-series, as used in previous studies (Marechal et al., 
2012; Betbeder et al., 2014 b). The originality of this study is the determination of the optimal number and key dates of SAR images to classify wetland vegetation formations at a 1:10,000 scale.

Wetland vegetation formations were classified excellently (kappa index $>0.90$ ) using five TerraSAR-X images acquired in late winter and spring. The most useful images for detecting wetland vegetation formations are those acquired during the high dynamics of plant growth and hydrodynamic processes (Fig. 6). Results of this study show that spring is the key season for mapping vegetation formations in wetlands in temperate climate zones. SAR images should be acquired during this critical period, i.e. from the end of winter until the beginning of summer, when hydrodynamic efficiency decreases and vegetation growth increases (Clement and Proctor, 2009). Previous ecological studies showed that hydrology is a dominant environmental variable that controls inter-annual variation in plant species composition in wetlands (Baldwin et al., 2001; Wassen et al., 2003). The duration of individual flood events and their frequency are highly important in segregating the plant communities (Casanova and Brock, 2000). Our results are consistent with the concept that flood disturbance during the growing season is an important determinant of species lower distribution boundaries in river floodplains (Van Eck et al., 2004). 


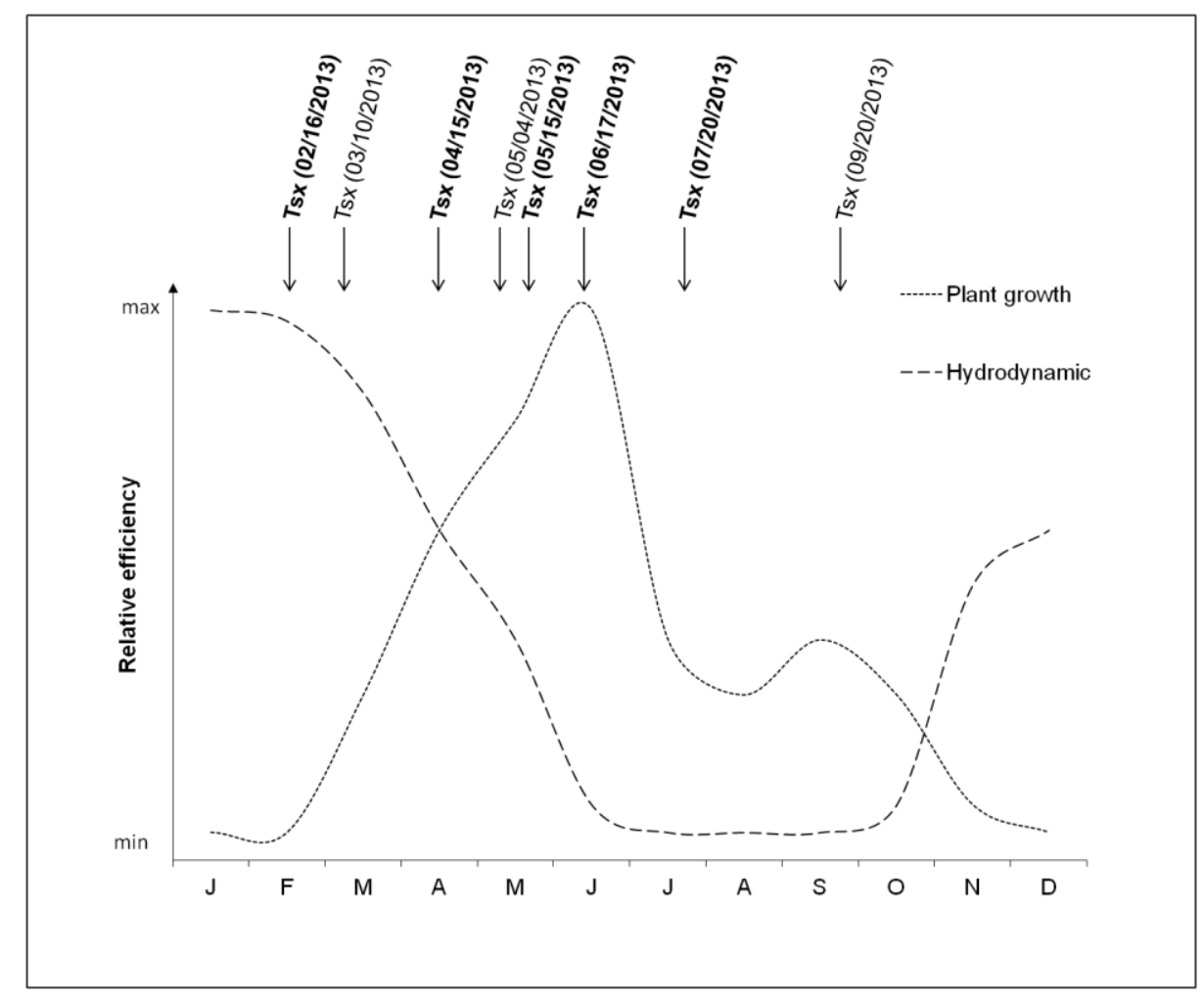

Figure 6. Schematic graph of two processes occurring in wetland areas under temperate climate conditions and acquisition dates of TerraSAR-X (Tsx) images

February is highly relevant for vegetation mapping as it corresponds to a peak in flooding. Thus, an image acquired in February detects mesophilic grasslands (i.e. non-flooded areas) accurately. Images from April, May and June determine the flood duration and thus indirectly certain vegetation formation types (i.e. long-flooded grasslands, meso-hygrophilic grasslands, and hygrophilic grasslands). May is generally considered as a key period for vegetation mapping since hydrodynamic processes remain active and vegetation growth is optimal (Harris and Bryant, 2009; Feilhauer et al., 2013; Rapinel et al., 2014). Open water can be detected accurately in July, when vegetation formations are dry. The optimal seasons for grassland mapping that we identified (i.e. end of winter, spring and the beginning of summer) differ from those of Schmidt et al. (2014) (i.e. late spring and late summer). These differences could have occurred because (i) we used SAR time-series, while Schmidt et al. (2014) used optical data; and (ii) we focused on the relationship between flood duration and vegetation distribution, while Schmidt et al. (2014) focused on grassland management (e.g. mowing, grazing) and therefore on vegetation structure. Thus, the choice of the optimal period(s) for image acquisition depends mainly on the dominant factors governing the spatial distribution of natural habitats (e.g. floods, management practices). 
Bargiel (2013) reported a classification accuracy of 76\% using 6 TerraSAR-X images (HH and VV) for 5 Natura 2000 classes for grassland mapping. Schuster et al. (2015) studied the potential of RapidEye and TerraSAR-X time-series for grassland habitat mapping. They showed that 15 TerraSAR-X or 5 RapidEye images are needed to reach $95 \%$ classification accuracy. In this study, we found a similar accuracy using only 5 TerraSAR-X images acquired during the end of winter and spring. These differences could be explained by (i) a longer acquisition period, (ii) use of a polarimetric parameter and (iii) the high level of concordance between acquisition dates and hydrological events. Our study corroborates the results of Franke et al. (2012), who demonstrated the importance of high spatial and temporal image resolutions during the vegetation growth period for characterizing grasslands.

In this study, 5 TerraSAR-X images were sufficient to map wetland vegetation. Satisfying results could also be obtained using only 2 TerraSAR-X images, but for only one combination of two dates (February and April, Fig. 3). We can notice that using using images acquired a few days before a flood event would not provide adequate results. The optimal number of images for wetland vegetation mapping depends mainly on the concordance between hydrological events (floods, drying, etc.) and the date of image acquisition. Flood duration, which is controlled by wetland management, also depends on weather events that are, by definition, unpredictable. This is why it is important to acquire several images between late winter and early summer (e.g. every 15 days). However, it is difficult to definitely set the optimal number of images required for vegetation mapping. This optimal number depends on (i) sensor configuration (e.g. incidence angle, revisiting time), (ii) precision of the habitat typology (e.g. Natura 2000 typology, physiognomy-based typology) and (iii) intra- and interannual variability in environmental factors (e.g. hydrological events, phenological status) (Schuster et al., 2015).

Most remote sensing studies focus on the backscattering coefficients of SAR images to detect grassland vegetation formations. Betbeder et al. (2014 b) and Lee et al. (2001) showed the importance of using polarimetric parameters instead of backscattering coefficients for wetland vegetation mapping. Our study confirms the potential of polarimetric data (i.e. SE) for wetland vegetation mapping at a fine scale. Polarimetric data can be derived from quad or dual-pol modes. Quad-pol mode leads actually to a smaller footprint (lower spatial resolution) than the dual-pol or single-pol mode (Lee and Pottier, 2009). Conversely, dual-pol mode allows extracting several polarimetric parameters with very high spatial 
resolutions (e.g. $1.5 \mathrm{~m}$ in our case), which is needed to map vegetation formations at a fine scale.

The SAR wavelengths (e.g. X-band, C-band, L-band) are also a key issue for habitat mapping. Our method was applied to a treeless herbaceous wetland because the Xband cannot penetrate a forest canopy to detect water-level changes beneath tree cover. Many studies have shown that only long wavelengths such as L-band or P-band can penetrate dense swamp forests (Hess et al., 2003; Betbeder et al. 2014 a). In contrast, we showed the potential of TerraSAR-X (X-band) and, more particularly, of a polarimetric parameter (SE) for grassland vegetation mapping in wetlands. Dusseux et al. (2014) obtained favorable results using polarimetric or intensity parameters derived from RADARSAT-2 C-band time-series to identify grasslands in an agricultural landscape (overall accuracies of $97 \%$ using CloudePottier decomposition parameters and $96 \%$ using a combination of $\mathrm{HH}, \mathrm{VV}$ and $\mathrm{HV}$ polarizations, respectively,). However, these same authors showed that RADARSAT-2 polarimetric time-series are unable to characterize grassland farming practices (e.g. mowing, grazing) (Dusseux et al., 2012). This could be explained not only by the SAR wavelengths but by the coarse spatial resolution of polarimetric RADARSAT-2 images $(7.0 \mathrm{~m})$. The recently launched Sentinel 1 sensor, which acquires SAR images with high spatial and temporal resolutions in the C-band, appears beneficial for studying the potential of the C-band for grassland mapping. However, for this purpose, the sensor has some limitations. First, Sentinel 1 provides, by default, images in the Interferometric Wide Swath (IW) mode with a spatial resolution of $5 \mathrm{~m} \times 20 \mathrm{~m}$; Stripmap-mode images with a spatial resolution of $5 \mathrm{~m} \times 5 \mathrm{~m}$ are more difficult to obtain, since this mode is rarely used (e.g. only for emergency management actions). Second, dual co-pol HH-VV configuration is not available for IW mode images, only HH-HV or VV-VH polarizations, while there is a high probability that $\mathrm{HV}$ or VH should be strongly affected by the noise equivalent sigma zero (NESZ) over wetland areas, and thus the Shannon entropy parameter would be affected. Instead of using only SAR data, combination of optical and SAR data, which has already demonstrated its ability to map grassland vegetation (Hill et al. 2005), could be investigated to combine the upcoming Sentinel 1 and Sentinel 2 data. In addition to this study, it might be interesting to investigate other SAR configuration modes (multi-frequency or multi-angular). With the upcoming BIOMASS and ALOS 2 sensors (P-band and L-band, respectively), it would be interesting to test this method on forested wetlands to monitor these crucial ecosystems. However, the BIOMASS sensor has a relatively coarse spatial resolution $(100-200 \mathrm{~m})$, which is suitable for 
forested wetland mapping at broad spatial scales over large areas, but not for identifying vegetation formations in herbaceous grasslands at a fine scale.

The classification nomenclature chosen in this study is more precise than those currently used in SAR studies for wetland mapping. Thus, many studies using SAR data, in particular intensity parameters (Hess et al., 2003), textural indexes (Gosselin et al., 2012) or polarimetric parameters (Schmitt et al., 2012), only consider main land-cover types (e.g. water, woods, flooded forest, non-flooded forest). Regarding the grassland classes, the classification obtained in this study is as accurate as those obtained in studies comparing vegetation and micro-topography using LIDAR data to classify wetland areas (Moeslund et al., 2011). Several studies indicated that vegetation species in wetlands can be identified using hyperspectral data (Schmidtlein et al., 2007). From the perspective of this study, this method could be assessed to classify wetland vegetation at the dominant-species level using TerraSAR-X data. However, this suggests conducting more accurate field work, for instance in collaboration with botanists, as recommended by Pettorelli et al. (2014), which highlights the need for interdisciplinary studies between remote sensing and ecology communities.

The results of this study provide interesting information, especially for watershed and wetland managers who monitor wetlands and flood dynamics (Jones et al., 2009). Since the cost of SAR images remains expensive $\left(140 € / \mathrm{km}^{2}\right)$ and the image processing is timeconsuming, our approach could help managers determine the optimal number of images required to achieve a precise wetland vegetation map and thus improve image acquisition planning. This study is a step aiming to fill the gap between methodological robustness and transferability when moving toward a more operational level.

\section{Conclusion}

This study explores the use of a complete monthly SAR time-series during a hydrological year to identify wetland vegetation formations. It highlights the periods (i.e. late winter and spring) relevant for mapping vegetation formations, in accordance with ecological studies that show that the most important season for assessing the distribution of vegetation formations is the spring drying period, i.e. between February and June in temperate climates. Results also indicate that a relationship can be established between vegetation formations and hydrodynamic processes with a short time-series (i.e. 5 dates). The use of high spatial resolution SAR images could predict spatio-temporal dynamic processes in wetlands, such as 
vegetation colonization. This study opens interesting perspectives for wetland management (e.g. restoration) and biodiversity studies.

\section{Acknowledgements}

This work was supported by the DIVA 3-AGRICONNECT program, the CNES and the DLR. We also wish to thank Cendrine Mony and Bernard Clément (Ecobio UMR 6553 CNRS) for providing us with the field data and Renan Le Roux for his help in statistics.

\section{References}

Agresti, A. 2007. An Introduction to Categorical Data Analysis. 2nd Edition. Hoboken, NJ: John Wiley \& Sons.

Alcantara, C., T. Kuemmerle, A. V. Prishchepov, V. C. Radeloff. 2012. «Mapping abandoned agriculture with multi-temporal MODIS satellite data ». Remote Sensing of Environment 124 : 334-47. doi:10.1016/j.rse.2012.05.019.

Alexandridis, T. K., E. Lazaridou, A. Tsirika, G. C. Zalidis. 2009. «Using Earth Observation to update a Natura 2000 habitat map for a wetland in Greece ». Journal of Environmental Management 90 (7): 2243-51. doi:10.1016/j.jenvman.2007.06.024.

Baldwin, A. H., M. S. Egnotovich, E. Clarke. 2001. «Hydrologic Change and Vegetation of Tidal Freshwater Marshes: Field, Greenhouse, and Seed-Bank Experiments ». Wetlands $21 \quad$ (4): $\quad 519-31 . \quad$ doi:10.1672/02775212(2001)021[0519:HCAVOT]2.0.CO;2.

Bargiel, D. 2013. "Capabilities of high resolution satellite radar for the detection of seminatural habitat structures and grasslands in agricultural landscapes ». Ecological Informatics 13 : 9-16. doi:10.1016/j.ecoinf.2012.10.004.

Betbeder, J., V. Gond, F. Frappart, N. Baghdadi, G. Briant, E. Bartholome. 2014. « Mapping of Central Africa Forested Wetlands Using Remote Sensing ». IEEE Journal of Selected Topics in Applied Earth Observations and Remote Sensing 7 (2): 531-42. doi:10.1109/JSTARS.2013.2269733.

Betbeder, J., S. Rapinel, T. Corpetti, E. Pottier, S. Corgne, L. Hubert-Moy. 2014. «Multitemporal classification of TerraSAR-X data for wetland vegetation mapping ». Journal of Applied Remote Sensing 8 (1): 083648-083648. doi:10.1117/1.JRS.8.083648.

Bouzillé, J.-B., E. Kernéis, A. Bonis, B. Touzard. 2001. «Vegetation and Ecological Gradients in Abandoned Salt Pans in Western France ». Journal of Vegetation Science 12 (2): 269-78. doi:10.2307/3236611.

Buck, O., A. Klink, V. E. García Millán, K. Pakzad, A. Müterthies. 2013. «Image Analysis Methods to Monitor Natura 2000 Habitats at Regional Scales - the MS. MONINA State Service Example in Schleswig-Holstein, Germany ». Photogrammetrie Fernerkundung - Geoinformation $2013 \quad$ (5): 415-26. doi:10.1127/14328364/2013/0188.

Casanova, M. T., and M. A. Brock. 2000. «How Do Depth, Duration and Frequency of Flooding Influence the Establishment of Wetland Plant Communities?». Plant Ecology 147 (2): 237-50. doi:10.1023/A:1009875226637. 
Chidley, T. R. E., and R. S. Drayton. 1986. "The use of SPOT-simulated imagery in hydrological mapping ». International Journal of Remote Sensing 7 (6): 791-99. doi:10.1080/01431168608954735.

Civco, D., J. Hurd, S. Prisloe, M. Gilmore. 2006. «Characterization of Coastal Wetland Systems using Multiple Remote Sensing Data Types and Analytical Techniques ». In IEEE International Conference on Geoscience and Remote Sensing Symposium, 2006. IGARSS 2006, 3442-46. doi:10.1109/IGARSS.2006.883.

Claverie, M., V. Demarez, B. Duchemin, O. Hagolle, D. Ducrot, C. Marais-Sicre, J.-F. Dejoux, et al. 2012. «Maize and sunflower biomass estimation in southwest France using high spatial and temporal resolution remote sensing data ». Remote Sensing of Environment 124 : 844-57. doi:10.1016/j.rse.2012.04.005.

Clement, B, E Maltby, D Hogan, R McInnes. 1996. «Relationships between vegetation, hydrology and soil properties in river marginal wetlands of the River Torridge basin ». In INRA, 79:305-14.

Clement, B. and Proctor, M.C.F., 2009. Ecological dynamics I: Vegetation as bioindicator and dynamic community. In Maltby E. ET Barker T., The wetlands handbook, Wiley-Blackwell, Oxford, pp,282-303.

Congalton, R. G. 1991. "A review of assessing the accuracy of classifications of remotely sensed data ». Remote Sensing of Environment 37 (1): 35-46. doi:10.1016/00344257(91)90048-B.

Corcoran, J., J. Knight, B. Brisco, S. Kaya, A. Cull, K. Murnaghan. 2011. « The integration of optical, topographic, and radar data for wetland mapping in northern Minnesota ». Canadian Journal of Remote Sensing 37 (5): 564-82.

Corgne, S., D. Dallon, G. Mercier. 2014. «Land use and land cover monitoring with multitemporal and multipolarization Radarsat data: Application to an intensive agricultural area (France) ». In Geoscience and Remote Sensing Symposium (IGARSS), 2014 IEEE International, 4239-42. doi:10.1109/IGARSS.2014.6947424.

Davranche, A., G. Lefebvre, B. Poulin. 2010. «Wetland monitoring using classification trees and SPOT-5 seasonal time series ». Remote Sensing of Environment 114 (3): 552-62. doi:10.1016/j.rse.2009.10.009.

Dumont, B., N. Rossignol, G. Loucougaray, P. Carrère, J. Chadoeuf, G. Fleurance, A. Bonis, et al. 2012. "When does grazing generate stable vegetation patterns in temperate pastures?». Agriculture, Ecosystems \& Environment 153: 50-56. doi:10.1016/j.agee.2012.03.003.

Duncan, P., A. J. M. Hewison, S. Houte, R. Rosoux, T. Tournebize, F. Dubs, F. Burel, V. Bretagnolle. 1999. "Long-Term Changes in Agricultural Practices and Wildfowling in an Internationally Important Wetland, and Their Effects on the Guild of Wintering Ducks ». Journal of Applied Ecology 36 (1): 11-23. doi:10.1046/j.13652664.1999.00363.x.

Dusseux, P., T. Corpetti, L. Hubert-Moy, S. Corgne. 2014. «Combined Use of MultiTemporal Optical and Radar Satellite Images for Grassland Monitoring ». Remote Sensing 6 (7): 6163-82. doi:10.3390/rs6076163.

Dusseux, P., X. Gong, T. Corpetti, L. Hubert-Moy, S. Corgne. 2012. « Contribution of radar images for grassland management identification ». In , 8531:853104-853104 - 7 . doi:10.1117/12.974547.

Ecker, K., L. T. Waser, M. Küchler. 2010. «Contribution of Multi-Source Remote Sensing Data to Predictive Mapping of Plant-Indicator Gradients within Swiss Mire Habitats ». Botanica Helvetica 120 (1): 29-42. doi:10.1007/s00035-010-0070-4. 
Eliasziw, M., and A. Donner. 1991. «Application of the McNemar Test to Non-Independent Matched Pair Data ». Statistics in Medicine 10 (12): 1981-91. doi:10.1002/sim.4780101211.

Evans, T. L., and M. Costa. 2013. «Landcover classification of the Lower Nhecolândia subregion of the Brazilian Pantanal Wetlands using ALOS/PALSAR, RADARSAT-2 and ENVISAT/ASAR imagery ». Remote Sensing of Environment $128: 118-37$. doi:10.1016/j.rse.2012.09.022.

Farghaly, D., E. Elba, B. Urban. 2014. « Observing the Middle Elbe Biosphere in Germany by Means of TerraSAR-X Images ». International Journal of Geosciences 05 (02): 196-205. doi:10.4236/ijg.2014.52021.

Feilhauer, H., F. Thonfeld, U. Faude, K. S. He, D.Rocchini, S. Schmidtlein. 2013. «Assessing floristic composition with multispectral sensors-A comparison based on monotemporal and multiseasonal field spectra ». International Journal of Applied Earth Observation and Geoinformation 21 : 218-29. doi:10.1016/j.jag.2012.09.002.

Fielding, A. H., and J. F. Bell. 1997. «A review of methods for the assessment of prediction errors in conservation presence/absence models ». Environmental Conservation 24 (01): $38-49$.

Foody, G. M. 2004. «Thematic Map Comparison». Photogrammetric Engineering \& Remote Sensing 70 (5): 627-33. doi:10.14358/PERS.70.5.627.

Foody, G.M., and A. Mathur. 2004. «A relative evaluation of multiclass image classification by support vector machines ». IEEE Transactions on Geoscience and Remote Sensing 42 (6): 1335-43. doi:10.1109/TGRS.2004.827257.

Franke, J., V. Keuck, F. Siegert. 2012. «Assessment of grassland use intensity by remote sensing to support conservation schemes ». Journal for Nature Conservation 20 (3): 125-34. doi:10.1016/j.jnc.2012.02.001.

Frappart, F., F. Seyler, J.-M. Martinez, J. G. León, A. Cazenave. 2005. «Floodplain water storage in the Negro River basin estimated from microwave remote sensing of inundation area and water levels ». Remote Sensing of Environment 99 (4): 387-99. doi:10.1016/j.rse.2005.08.016.

Gosselin, G, R. Touzi, F Cavayas. 2012. «Wetland Characterization and Classification using Polarimetric Radarsat-2 capability for the Lac Saint-Pierre region (Canada) ». In Proceedings of Geomatrix'12. 26-29 February 2012, 4. Mumbai, India.

Gren, I.-M., C. Folke, K.Turner, I. Batemen. 1994. «Primary and Secondary Values of Wetland Ecosystems ». Environmental and Resource Economics 4 (1): 55-74. doi:10.1007/BF00691932.

Harris, A., and R. G. Bryant. 2009. « A multi-scale remote sensing approach for monitoring northern peatland hydrology: Present possibilities and future challenges ». Journal of Environmental Management, The GlobWetland Symposium: Looking at wetlands from space The GlobWetland Symposium, $90 \quad$ (7): 2178-88. doi:10.1016/j.jenvman.2007.06.025.

Hess, L., J. M Melack, E. M.L.M Novo, C. C.F Barbosa, M. Gastil. 2003. «Dual-season mapping of wetland inundation and vegetation for the central Amazon basin ». Remote Sensing of Environment 87 (4): 404-28. doi:10.1016/j.rse.2003.04.001.

Hill, M.J., C.J. Ticehurst, Jong-Sen Lee, M.R. Grunes, G.E. Donald, D. Henry. 2005. «Integration of optical and radar classifications for mapping pasture type in Western Australia ». IEEE Transactions on Geoscience and Remote Sensing 43 (7): 1665-81. doi:10.1109/TGRS.2005.846868.

Jones, K., Y. Lanthier, P. van der Voet, E. van Valkengoed, D. Taylor, D. Fernández-Prieto. 2009. "Monitoring and assessment of wetlands using Earth Observation: The 
GlobWetland project». Journal of Environmental Management, The GlobWetland Symposium: Looking at wetlands from space The GlobWetland Symposium, 90 (7): 2154-69. doi:10.1016/j.jenvman.2007.07.037.

Keddy, P. A., L. H. Fraser, A. I. Solomeshch, W. J. Junk, D. R. Campbell, M. T. K. Arroyo, C. J. R. Alho. 2009. "Wet and Wonderful: The World's Largest Wetlands Are Conservation Priorities ». BioScience 59 (1): 39-51. doi:10.1525/bio.2009.59.1.8.

Lang, S., C. Corbane, L Pernkopf. 2013. «Earth Observation for Habitat and Biodiversity Monitoring ». In GI_Forum 2013. Creating the GISociety, 2013:478-86. Wien: Verlag der Österreichischen Akademie der Wissenschaften. doi:10.1553/giscience2013s478.

Lee, J.-S. 1981. «Speckle analysis and smoothing of synthetic aperture radar images ». Computer Graphics and Image Processing 17 (1): 24-32. doi:10.1016/S0146664X(81)80005-6.

Lee, J.-S., M.R. Grunes, E. Pottier. 2001. "Quantitative comparison of classification capability: fully polarimetric versus dual and single-polarization SAR ». IEEE Transactions on Geoscience and Remote Sensing 39 (11): 2343-51. doi:10.1109/36.964970.

Lee, J.-S., and E. Pottier. 2009. Polarimetric Radar Imaging: From Basics to Applications. CRC Press.

Loucougaray, G., A. Bonis, J.-B. Bouzillé. 2004. «Effects of grazing by horses and/or cattle on the diversity of coastal grasslands in western France ». Biological Conservation 116 (1): 59-71. doi:10.1016/S0006-3207(03)00177-0.

Maltby, E., and T. Barker. 2009. The Wetlands Handbook. Wiley-Blackwell. Oxford.

Marechal, C., E. Pottier, L. Hubert-Moy, S. Rapinel. 2012. "One year wetland survey investigations from quad-pol RADARSAT-2 time-series SAR images ». Canadian Journal of Remote Sensing 38 (3): 240-52.

Mitsch, W.J, and J.G Gosselink. Wetlands, 4th edition. 4th edition. Oxford: Wiley.

Moeslund, J. E., L. Arge, P. K. Bøcher, B. Nygaard, J.-C. Svenning. 2011. « Geographically Comprehensive Assessment of Salt-Meadow Vegetation-Elevation Relations Using LiDAR ». Wetlands 31 (3): 471-82. doi:10.1007/s13157-011-0179-2.

Mountrakis, G., J. Im, C. Ogole. 2011. «Support vector machines in remote sensing: A review ». ISPRS Journal of Photogrammetry and Remote Sensing 66 (3): 247-59. doi:10.1016/j.isprsjprs.2010.11.001.

Murakami, T., S. Ogawa, N. Ishitsuka, K. Kumagai, G. Saito. 2001. « Crop discrimination with multitemporal SPOT/HRV data in the Saga Plains, Japan ». International Journal of Remote Sensing 22 (7): 1335-48. doi:10.1080/01431160151144378.

Nagendra, H., R. Lucas, J. P. Honrado, R. H. G. Jongman, C. Tarantino, M. Adamo, P. Mairota. 2013. «Remote sensing for conservation monitoring: Assessing protected areas, habitat extent, habitat condition, species diversity, and threats ». Ecological Indicators, Biodiversity Monitoring, 33 : 45-59. doi:10.1016/j.ecolind.2012.09.014.

Pettorelli, N., W. F. Laurance, T. G. O’Brien, M. Wegmann, H. Nagendra, W. Turner. 2014. «Satellite Remote Sensing for Applied Ecologists: Opportunities and Challenges ». Journal of Applied Ecology, n/a - n/a. doi:10.1111/1365-2664.12261.

Pottier, E., and L. Ferro-Famil. 2012. "PolSARPro V5.0: An ESA educational toolbox used for self-education in the field of POLSAR and POL-INSAR data analysis ». In Geoscience and Remote Sensing Symposium (IGARSS), 2012 IEEE International, 7377-80. doi:10.1109/IGARSS.2012.6351925.

Rapinel, S., B. Clément, S. Magnanon, V. Sellin, L. Hubert-Moy. 2014. «Identification and mapping of natural vegetation on a coastal site using a Worldview-2 satellite image ». 
Journal of Environmental Management 144: 236-46. doi:10.1016/j.jenvman.2014.05.027.

Rapinel, S, L Hubert-Moy, B Clément. in press. "Combined use of LiDAR data and multispectral earth observation imagery for wetland habitat mapping ». Int. J. Appl. Earth Obs. Geoinformation. doi:10.1016/j.jag.2014.09.002.

Réfrégier, P., and J. Morio. 2006. «Shannon entropy of partially polarized and partially coherent light with Gaussian fluctuations ». Journal of the Optical Society of America A 23 (12): 3036-44. doi:10.1364/JOSAA.23.003036.

Sader, S. A., D. Ahl, W.-S. Liou. 1995. «Accuracy of landsat-TM and GIS rule-based methods for forest wetland classification in Maine ». Remote Sensing of Environment 53 (3): 133-44. doi:10.1016/0034-4257(95)00085-F.

Sawtschuk, J., and F. Bioret. 2012. "Analyse diachronique de la dynamique spatiale de la végétation de l'estuaire de la Loire ». Photo interprétation 48 (3): 15-28.

Schmidtlein, S., P. Zimmermann, R. Schüpferling, C. Weiß. 2007. «Mapping the Floristic Continuum: Ordination Space Position Estimated from Imaging Spectroscopy ». Journal of Vegetation Science 18 (1): 131-40. doi:10.1111/j.16541103.2007.tb02523.x.

Schmidt, T., C. Schuster, B. Kleinschmit, M. Forster. 2014. «Evaluating an Intra-Annual Time Series for Grassland Classification; How Many Acquisitions and What Seasonal Origin Are Optimal?». IEEE Journal of Selected Topics in Applied Earth Observations and Remote Sensing $7 \quad$ (8): 3428-39. doi:10.1109/JSTARS.2014.2347203.

Schmitt, A., T. Leichtle, M. Huber, A. Roth. 2012. «On the use of dual-co-polarized TerraSAR-X data for wetland monitoring ». ISPRS - International Archives of the Photogrammetry, Remote Sensing and Spatial Information Sciences XXXIX-B7: 341-44. doi:10.5194/isprsarchives-XXXIX-B7-341-2012.

Schuster, C., T. Schmidt, C. Conrad, B. Kleinschmit, M. Förster. 2015. «Grassland habitat mapping by intra-annual time series analysis - Comparison of RapidEye and TerraSAR-X satellite data ». International Journal of Applied Earth Observation and Geoinformation 34 : 25-34. doi:10.1016/j.jag.2014.06.004.

Stenzel, S., H.Feilhauer, B. Mack, A. Metz, S. Schmidtlein. 2014. «Remote sensing of scattered Natura 2000 habitats using a one-class classifier ». International Journal of Applied Earth Observation and Geoinformation 33: 211-17. doi:10.1016/j.jag.2014.05.012.

Tigges, J., T. Lakes, P. Hostert. 2013. «Urban vegetation classification: Benefits of multitemporal RapidEye satellite data ». Remote Sensing of Environment 136 : 6675. doi:10.1016/j.rse.2013.05.001.

Touzi, R., W M Boerner, J S Lee, E. Lueneburg. 2004. «A review of polarimetry in the context of synthetic aperture radar: concepts and information extraction ». Canadian Journal of Remote Sensing 30 (3): 380-407. doi:10.5589/m04-013.

Vanden Borre, J., D. Paelinckx, C. A. Mücher, L. Kooistra, B. Haest, G. De Blust, A. M. Schmidt. 2011. "Integrating remote sensing in Natura 2000 habitat monitoring: Prospects on the way forward ». Journal for Nature Conservation 19 (2): 116-25. doi:10.1016/j.jnc.2010.07.003.

Van Eck, W. H. J. M., H. M. Van De Steeg, C. W. P. M. Blom, H. De Kroon. 2004. « Is Tolerance to Summer Flooding Correlated with Distribution Patterns in River Floodplains? A Comparative Study of 20 Terrestrial Grassland Species ». Oikos 107 (2): 393-405. doi:10.1111/j.0030-1299.2004.13083.x. 
Van Niel, T. G., and T. R. McVicar. 2004. «Determining temporal windows for crop discrimination with remote sensing: a case study in south-eastern Australia ». Computers and Electronics in Agriculture 45 (1-3): 91-08. doi:10.1016/j.compag.2004.06.003.

Verbesselt, J., R. Hyndman, G. Newnham, D. Culvenor. 2010. «Detecting trend and seasonal changes in satellite image time series ». Remote Sensing of Environment 114 (1): 10615. doi:10.1016/j.rse.2009.08.014.

Wassen, M. J., W. H. M. Peeters, H. Olde Venterink. 2003. «Patterns in Vegetation, Hydrology, and Nutrient Availability in an Undisturbed River Floodplain in Poland ». Plant Ecology 165 (1): 27-43. doi:10.1023/A:1021493327180.

Zhang, T. 2001. «An Introduction to Support Vector Machines and Other Kernel-Based Learning Methods ». AI Magazine 22 (2): 103. doi:10.1609/aimag.v22i2.1566.

Zheng, S, J Liu, J W Tian. 2004. «A new efficient SVM-based edge detection method». Pattern Recognition Letters 25 (10): 1143-54. doi:10.1016/j.patrec.2004.03.009. 